\title{
Spinoglenoid notched ganglion cyst with a subtle SLAP tear, and acromio-humeral impingement findings veiling the real radiological picture: An MRI lesson
}

\section{Emrah Dogan ( $\nabla$ emrahdogan@mu.edu.tr)}

Muğla Sıtkı Koçman Üniversitesi: Mugla Sitki Kocman Universitesi https://orcid.org/0000-0002-94462294

Hüseyin Aydoğmuş

Muğla Sıtkı Koçman Üniversitesi: Mugla Sitki Kocman Universitesi Sinem Aydoğmuş

Muğla Sıtkı Koçman Üniversitesi: Mugla Sitki Kocman Universitesi

\section{Research Article}

Keywords: Spinoglenoid cyst, SLAP, shoulder, magnetic resonance imaging

Posted Date: May 17th, 2021

DOl: https://doi.org/10.21203/rs.3.rs-521351/v1

License: (c) (1) This work is licensed under a Creative Commons Attribution 4.0 International License.

Read Full License 


\section{Abstract}

Spinoglenoid notch ganglion cyst (SNGC) is a rare shoulder cystic lesion. It is usually associated with superior labrum anteroposterior (SLAP) tears. SNGC can typically cause compression of the suprascapular nerve at the spinoglenoid notch. The aim of our paper is to draw attention to the relation of SNGC cyst with SLAP tears and to raise awareness so that accompanying low-grade labral tears are not overlooked. In addition, since these findings usually accompanied by acromioclavicular joint hypertrophy, the clinic table accidentally can be linked with impingement. The patient applied to our hospital with a complaint of weakness and mild pain in his arm. External rotation was difficult in the examination. Linear type I SLAP tear associated with degeneration was detected. The radiological findings of SLAPtear were subtle, and there were additional findings that could be interpreted as impingement. A lobulated and multiloculated cyst was observed in the supraglenoid notch.

\section{Introduction}

Spinoglenoid notch ganglion cyst (SNGC) is a rare juxta-articular cystic lesion seen in the dorsal of the glenohumeral joint ${ }^{1}$. The suprascapular nerve pass from the $S G$ notch. Space-occupying lesions in this anatomical location compress the suprascapular nerve. Therefore, it may cause the weakness of muscle in the region innervated by the nerve (infraspinatus muscle) and clinical findings (weakness of muscle in early-stage, muscle atrophy in advanced stage) due to nerve compression ${ }^{2}$. The aim of our paper is to draw attention to the relation of SNGC cyst with superior labrum anteroposterior (SLAP) tears and to raise awareness so that accompanying low-grade labral tears are not overlooked. In addition, since these findings usually accompanied by acromioclavicular joint hypertrophy, the clinic table accidentally can be linked with impingement. We presented a 56-year-old male patient with a cyst in the supraglenoid notch accompanied by an X-ray graph and Magnetic resonance imaging (MRI) findings.

\section{Case Report}

The patient was admitted to our hospital with a complaint of arm weakness. In the anamnesis, there was a pain in the back and shoulder on the same side, there was no history of trauma. External rotation was difficult on examination. EMG was offered but could not be done. The acromioclavicular joint was hypertrophic on radiography [Figure 1a]. Osteophytes were present in the bone corners. Acromio-humeral distance was normal. MRI showed that the increased superior labrum signal fat-suppressed T2 sequence in favour of labral degeneration. A linear subtle superior labrum tear was detected. The tear was evaluated as Type 1 SLAP tear [Figure 1b]. The acromion was type II. Acromioclavicular joint hypertrophy was more clearly demonstrated on MRI [Figure 1c]. A lobulated and multilocular cyst at a distance of $12 \times 15 \mathrm{~mm}$ was observed at the supraglenoid notch [Figure 1d]. The consent form was signed by the patient in 20.08.2020.

\section{Discussion}


$S N G C$ is a ganglion cyst observed in the $S G$ notch that described according to the localization ${ }^{3}$. The majority of SNGCS are associated with a labral tear ${ }^{2}$, and especially with $S L A P$ tears. It may be overlooked when the tear is low grade ${ }^{4}$. In untreated cases, supraspinatus atrophy develops in the advanced period SLAP classified in ten groups but first seven types are used in general [Figure 2].

The most common examination findings include weakness of external rotation and posterior shoulder tenderness due to suprascapular nerve compression in the SG notch. Radiologically; The ganglion cyst is typically seen in low-signal in T1-weighted sequences and high-signal in T2-weighted sequences on MRI due to its fluid content, and can be unilocular or multilocular ${ }^{2}$. Paralabral cyst extending to the $S G$ notch and $S G$ notch varices are in the differential diagnosis ${ }^{5}$.

\section{Conclusion}

The cases with SNGC should be evaluated more detailed radiologically in terms of labral tears in order not to overlook accompanying low-grade labral tears. Since acromioclavicular joint hypertrophy is often present in these patients, pain may be mistakenly attributed with impingement.

\section{Declarations}

i. Funding:The author(s) received no financial support for the research, authorship, and/or publication of this article.

ii. Conflicts of interest/Competing interests: No conflict of interest between authors.

iii. Ethics approval: The consent form was signed by the patient in 20.08.2020. Apart from this, ethics committee approval was not obtained.

iv. Consent to participate (include appropriate statements): The consent form was signed by the patient in 20.08.2020.

v. Consent for publication (include appropriate statements): The authors accepted all of the journal rules for publication and gives up all about the paper.

vi. Availability of data and material: The data of the patient were obtained from the hospital PACS system and the local data system called Kardelen used by our hospital.

vii. Code availability: Licensed programs and free software used by Muğla Sıtkı Koçman University were used for this paper.

\section{viii. Authors' contributions:}

Emrah Doğan: Evaluating of the radiological findings, writing the case report, responsible author. 
Hüseyin Aydoğmuş: Evaluating of clinical finding.

Sinem Aydoğmuş: Evaluating of the radiological findings.

\section{References}

1.Burks R. Editorial Commentary: To Cyst or Not to Cyst: Shoulder SLAP Lesions With Concomitant Spinoglenoid Notch Ganglion Cysts. Arthroscopy. 2018 Jul;34(7):2254-2255. doi:

10.1016/j.arthro.2018.02.043. PMID: 29976439.

2.Piatt BE, Hawkins RJ, Fritz RC, Ho CP, Wolf E, Schickendantz M. Clinical evaluation and treatment of spinoglenoid notch ganglion cysts. J Shoulder Elbow Surg. 2002 Nov-Dec;11(6):600-604. doi: 10.1067/mse.2002.127094. PMID: 12469086.

3.Yanny S, Toms AP. MR patterns of denervation around the shoulder. AJR Am J Roentgenol. 2010 Aug;195(2): W157-163. doi: 10.2214/AJR.09.4127. PMID: 20651176.

4.Westerheide KJ, Karzel RP. Ganglion cysts of the shoulder: technique of arthroscopic decompression and fixation of associated type II superior labral anterior to posterior lesions. Orthop Clin North Am. 2003 Oct;34(4):521-528. doi: 10.1016/s0030-5898(03)00102-0. PMID: 14984191.

5.Linda DD, Harish S, Stewart BG et-al. Multimodality imaging of peripheral neuropathies of the upper limb and brachial plexus. Radiographics. 2010;30 (5): 1373-1400. doi:10.1148/rg.305095169- Pubmed citation

\section{Figures}




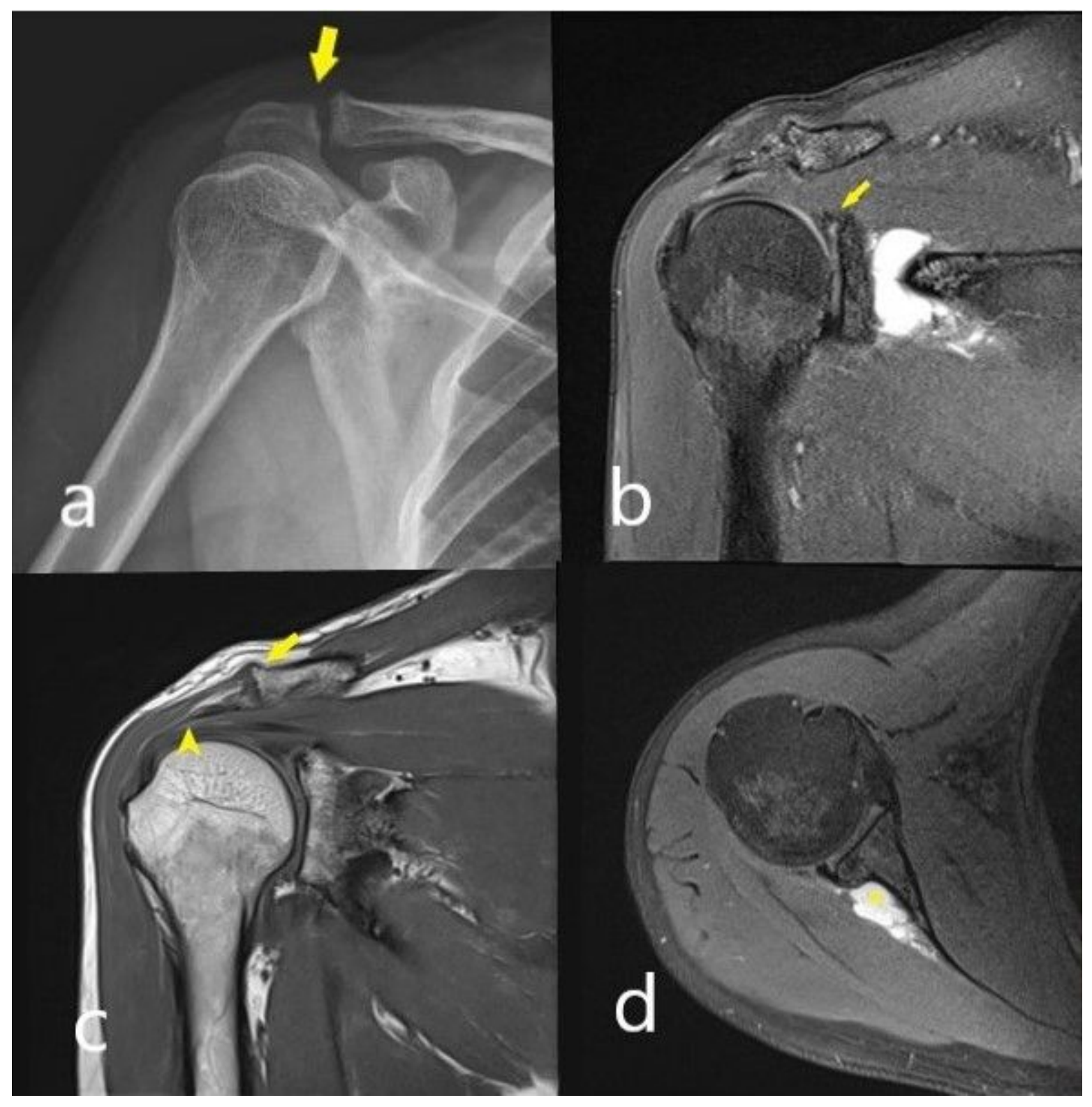

\section{Figure 1}

Figure1a: Acromioclavicular joint hypertrophy (arrow) on X-ray imaging. Figure1b: Superior labrum anteroposterior (SLAP) tear (arrow) and bilobular cyst on sagittal plane of T2 fat-suppressed image. Figure1c: Acromioclavicular joint hypertrophy (arrow) and supraspinatus muscle's tendinosis on T1 sagittal image in MRI. Figure1d: SG cyst in the notch (mark) on oblique-axial plane T2 fat suppressed image. 


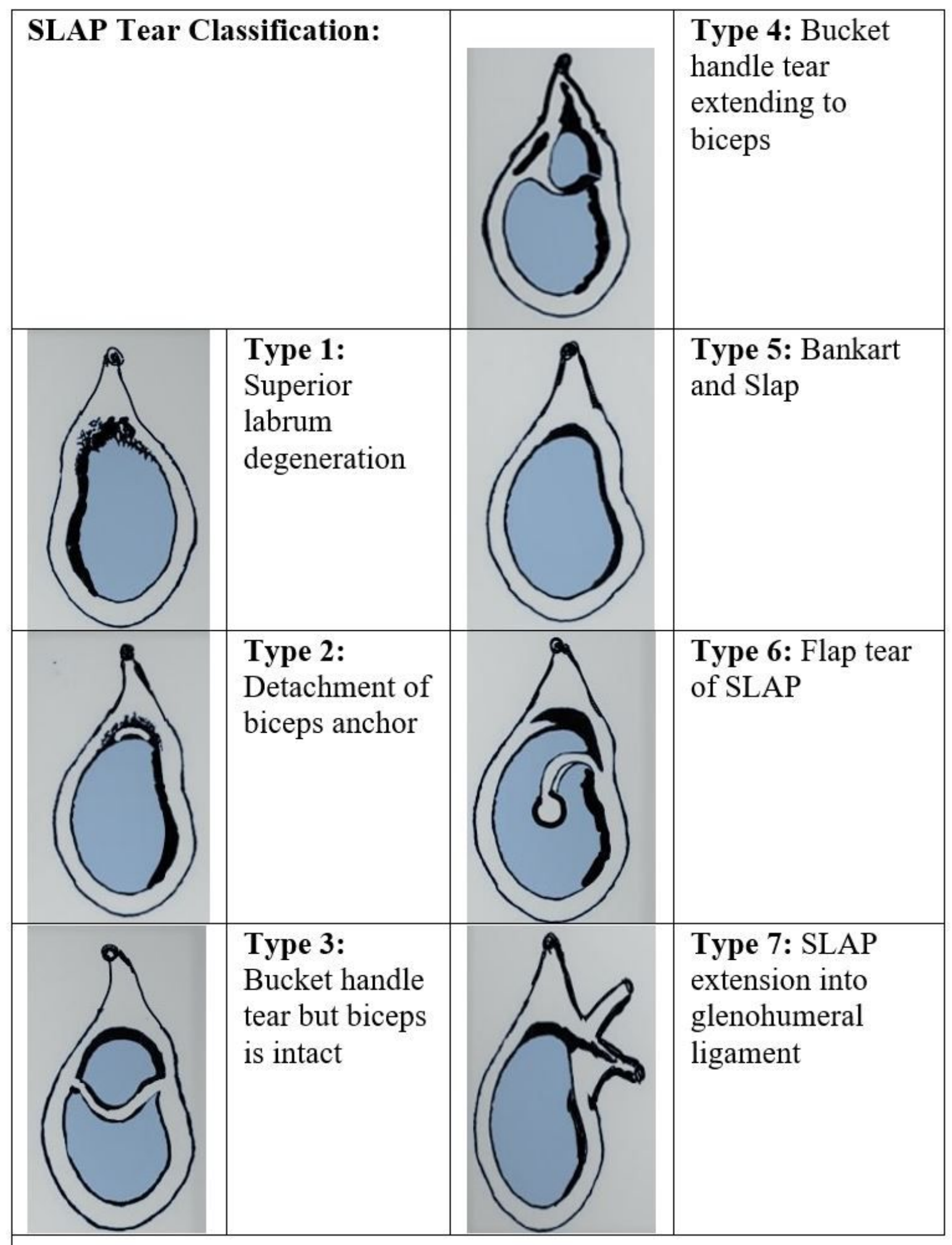

Figure 2

The classification of SLAP tears. 